05

\title{
Метод анализа доменной структуры в микрочастицах магнитных порошков
}

\author{
() Ш.М. Алиев, Ж.Г. Ибаев \\ Институт физики им. Х.И. Амирханова ДагНЦ РАН, Махачкала, Россия \\ ๑ E-mail: ibaev77@mail.ru
}

Поступило в Редакцию 29 мая 2019г.

В окончательной редакции 24 июня 2019г.

Принято к публикации 24 июня 2019г.

\begin{abstract}
Предложен метод анализа доменной структуры в микрочастицах магнитных порошков, основанный на эффекте Мессбауэра. Экспериментально метод проверен на частицах порошка феррита-граната гадолиния $\mathrm{Gd}_{3} \mathrm{Fe}_{5} \mathrm{O}_{12}$ диаметром $40 \pm 5 \mu \mathrm{m}$ в области точки магнитной компенсации $T_{c m}\left(T_{c m}=286 \mathrm{~K}\right)$. Показано, что вблизи $T_{c m}$ частицы феррита однодоменны, с удалением от $T_{c m}$ частицы переходят в многодоменное состояние.
\end{abstract}

Ключевые слова: доменная структура, однодоменные частицы, ферриты, точка магнитной компенсации, эффект Мессбауэра.

DOI: 10.21883/PJTF.2019.19.48319.17897

Известно, что при сильном измельчении магнетика возникают однодоменные частицы. Физическая причина этого явления заключается в том, что при уменьшении размера магнитостатическая энергия частицы, пропорциональная объему частицы, убывает быстрее, чем энергия доменных границ, пропорциональная площади поверхности частицы. При некотором критическом размере энергетически выгодным становится однодоменное состояние. Критический диаметр, при котором частица переходит из многодоменного состояния в однодоменное, определяется с помощью выражения [1]:

$$
d_{c r}=\frac{9}{2 \pi} \frac{\sigma}{M_{s}^{2}}
$$

где $\sigma$ - плотность энергии доменной границы, $M_{s}-$ самопроизвольная намагниченность частицы. Магнитные порошки из однодоменных частиц нашли широкое техническое применение [2,3].

Для наблюдения доменной структуры в микрочастицах магнетиков обычно применяются магнитооптические методы, основанные на эффектах Керра и Фарадея [1]. В [4] на основе эффекта Мессбауэра был предложен метод анализа доменной структуры в монокристаллическом образце феррита, обладающего точкой магнитной компенсации $T_{c m}$. В настоящей работе на основе эффекта Мессбауэра предлагается метод анализа доменной структуры в микрочастицах магнитных порошков. Отметим, что мессбауэровская спектроскопия успешно применяется для исследования структурных и магнитных свойств магнитных материалов, содержащих частицы или кластеры нанометрового размера $[5,6]$. Интерес к системам магнитных частиц или кластеров малых размеров обусловлен прежде всего широкой областью их применения в современных нанотехнологиях $[7,8]$.
Рассмотрим ансамбль однодоменных частиц, изотропно распределенных в пространстве. Если намагнитить этот ансамбль частиц до насыщения, а затем выключить намагничивающее поле $H$, то максимальный угол $\theta_{m}$ отклонения векторов намагниченности частиц от направления приложенного поля будет равен углу $\alpha$ между осями трудного и легкого намагничивания в данном магнетике. Для магнетиков с кубической анизотропией $\alpha=55^{\circ}$, а для магнетиков с одноосной анизотропией $\alpha=90^{\circ}$. Таким образом, в состоянии остаточной намагниченности векторы намагниченности однодоменных частиц изотропно распределяются в телесном угле $\Omega=2 \theta_{m}=2 \alpha$.

Если же в частицах существует доменная структура, то $\theta_{m}>\alpha$, так как в доменной структуре кроме доменов, векторы намагниченности которых направлены вдоль осей легкого намагничивания, существуют замыкающие домены и доменные стенки, в которых магнитные моменты направлены под углом к осям легкого намагничивания.

Известно, что относительные площади линий зеемановского расщепления мессбауэровского спектра ядер ${ }^{57} \mathrm{Fe}$ в однородно намагниченном образце зависят от угла $\theta$ между направлением распространения $\gamma$-лучей и направлением намагниченности в образце [9]:

$$
\begin{gathered}
S_{1,6}=3\left(1+\cos ^{2} \theta\right), \\
S_{2,5}=4 \sin ^{2} \theta \\
S_{3,4}=1+\cos ^{2} \theta .
\end{gathered}
$$

Пусть геометрия эксперимента такова, что направление распространения $\gamma$-лучей совпадает с направлением $H$. Тогда для величины $k$, равной отношению площадей второй к первой или пятой к шестой линии поглощения 


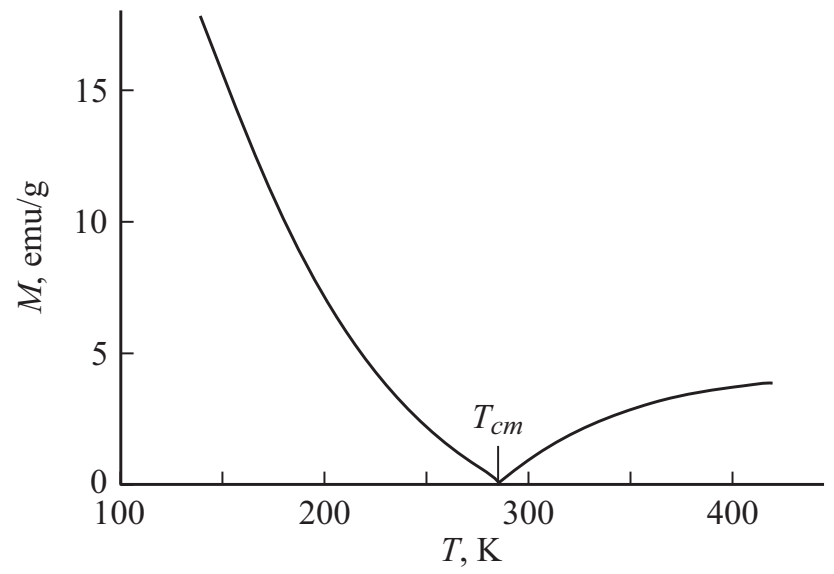

Рис. 1. Температурная зависимость намагниченности насыщения феррита $\mathrm{Gd}_{3} \mathrm{Fe}_{5} \mathrm{O}_{12}$.

мессбауэровского спектра ядер ${ }^{57} \mathrm{Fe}$ в образце, можно записать

$$
k=\frac{S_{2,5}}{S_{1,6}}=\frac{4\left(1-\overline{\cos ^{2}} \theta_{i}\right)}{3\left(1+\overline{\cos ^{2}} \theta_{i}\right)},
$$

где $\theta_{i}$ - угол между направлением распространения $\gamma$-лучей и направлением намагниченности $i$-частицы $\left(0 \leqslant \theta_{i} \leqslant \theta_{m}\right)$ :

$$
\begin{aligned}
\overline{\cos ^{2}} \theta_{i} & =\frac{\int_{0}^{\theta_{m}} \int_{0}^{2 \pi} \cos ^{2} \theta \sin \theta d \theta d \varphi}{\int_{0}^{\theta_{m}} \int_{0}^{2 \pi} \sin \theta d \theta d \varphi} \\
= & \frac{\cos ^{3} \theta_{m}-1}{3\left(\cos \theta_{m}-1\right)} .
\end{aligned}
$$

Для однодоменных частиц получим $\overline{\cos ^{2}} \theta_{i}=0.63$ (кубическая анизотропия) и $\overline{\cos ^{2}} \theta_{i}=0.33$ (одноосная анизотропия). Подставляя эти значения в (3), приходим к следующим критериям: если $k+\Delta k \leqslant 0.30$ (кубическая анизотропия) и $k+\Delta k \leqslant 0.67$ (одноосная анизотропия), то частицы порошка однодоменны; $\Delta k-$ экспериментальная ошибка в определении параметра $k$. Если же $k-\Delta k>0.30$ (кубическая анизотропия) и $k-\Delta k>0.67$ (одноосная анизотропия), то в частицах порошка существует доменная структура, причем по величине параметра $k$ можно судить об относительном количестве доменов в частицах.

Для постановки эксперимента наиболее благоприятными магнетиками являются редкоземельные ферритыгранаты (РЗФГ), имеющие точку магнитной компенсации $T_{c m}$. Действительно, вблизи $T_{c m}$ вследствие малой величины самопроизвольной намагниченности довольно крупные частицы РЗФГ могут стать однодоменными [10]. Кроме того, частицы однодоменные вблизи $T_{c m}$ переходят в многодоменное состояние при удалении от $T_{c m}$. Поэтому, постепенно отдаляясь от $T_{c m}$, можно экспериментально проверить справедливость найденных критериев. Отметим, что интерес к РЗФГ связан с перспективой создания на основе доменной структуры этих ферримагнетиков материалов для элементной базы приборов магнитной микроэлектроники [11-13].

Метод проверялся на частицах из монокристаллического феррита $\mathrm{Gd}_{3} \mathrm{Fe}_{5} \mathrm{O}_{12}$, обладающего кубической анизотропией, изготовленного по стандартной технологии из чистых исходных окислов $\mathrm{Gd}_{2} \mathrm{O}_{3}$ и $\mathrm{Fe}_{2} \mathrm{O}_{3}$ [14]. Измерения намагниченности проводились в интервале температур $150-400 \mathrm{~K}$ на вибрационном магнитометpe BM2-А. Было установлено, что точка компенсации феррита $T_{c m}=286 \mathrm{~K}$ (рис. 1). Мессбауэровские спектры ядер ${ }^{57} \mathrm{Fe}$ записывались на спектрометре ЯГРС-4М с источником $\gamma$-излучения ${ }^{57} \mathrm{Co}(\mathrm{Cr})$. При пропускании измельченного в агатовой ступке порошка монокристаллического феррита через набор тонких сит были получены частицы сферической формы диаметром $d=40 \pm 5 \mu \mathrm{m}$. Из порошка этих частиц изготовлялся образец - поглотитель для мессбауэровских измерений - путем осаждения порошка в смеси клея на тонкий слюдяной

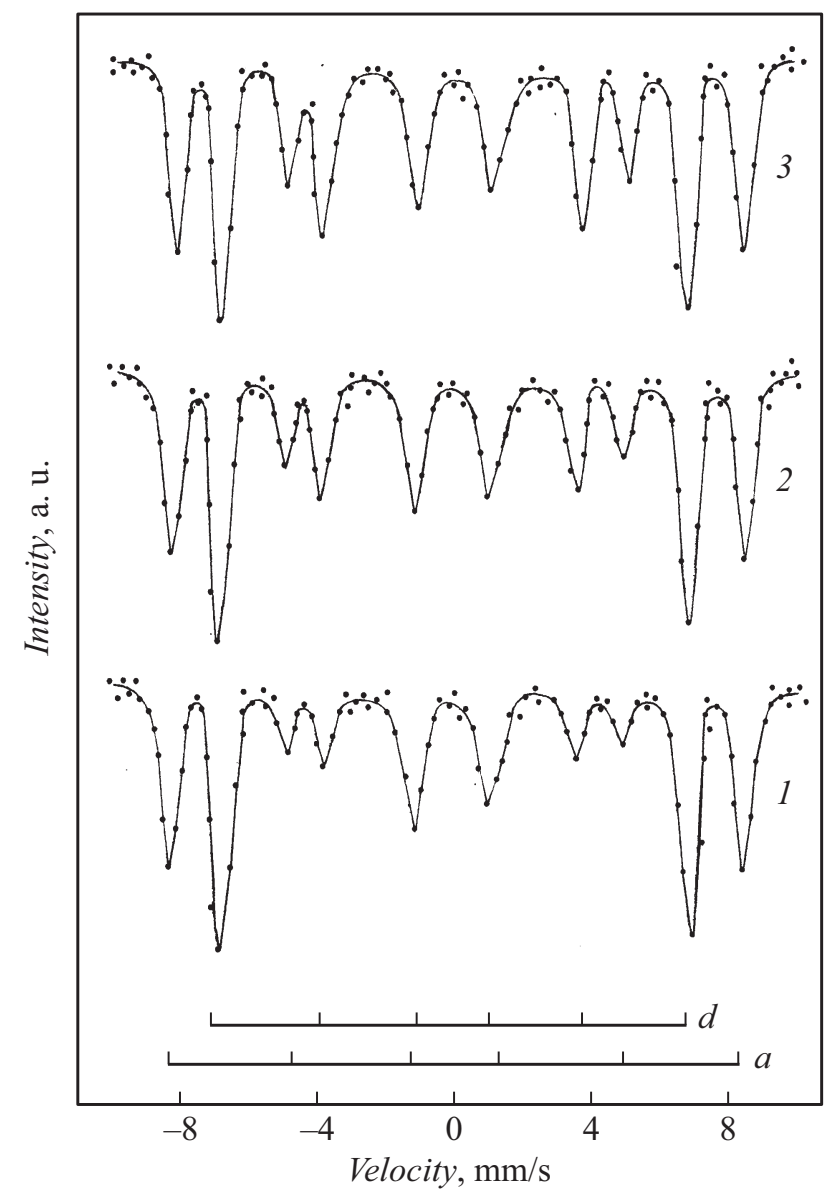

Рис. 2. Мессбауэровские спектры образца из порошка частиц $(d=40 \pm 5 \mu \mathrm{m})$ монокристаллического феррита $\mathrm{Gd}_{3} \mathrm{Fe}_{5} \mathrm{O}_{12}$. Образец приводился в состояние остаточной намагниченности в направлении, перпендикулярном плоскости образца, при $T=T_{c m}+2 \mathrm{~K}(1), T=T_{c m}+33 \mathrm{~K}(2), T=T_{c m}+45 \mathrm{~K}(3)$. 


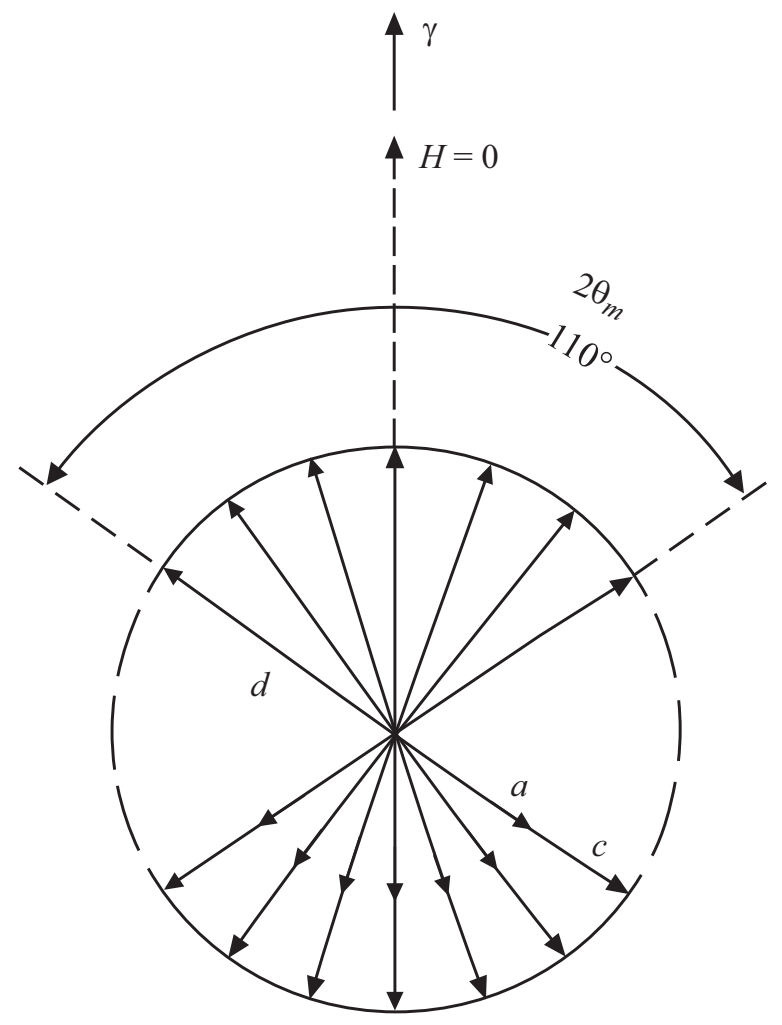

Рис. 3. Пространственное распределение магнитных моментов ионов в $a$-, $d$ - и $c$-подрешетках образца из микрочастиц феррита $\mathrm{Gd}_{3} \mathrm{Fe}_{5} \mathrm{O}_{12}$ в состоянии остаточной намагниченности вблизи $T_{c m}$.

диск. Толщина поглотителя по естественному железу составляла $20 \mathrm{mg} / \mathrm{cm}^{2}$. Для проведения температурных измерений образец помещался в комбинированную с криостатом температурную камеру с плавной регулировкой температур в интервале $120-500 \mathrm{~K}$. Автоматическая терморегулировка обеспечивала поддержание заданной температуры с точностью $\pm 0.5 \mathrm{~K}$. Перед измерением мессбауэровского спектра образец приводился в состояние остаточной намагниченности при заданной температуре. Температура образца доводилась до необходимого значения, затем магнитное поле, приложенное перпендикулярно плоскости образца, увеличивалось от нуля до величины $H_{S}=2 \mathrm{kOe}$, достаточной для магнитного насыщения образца, после чего уменьшалось до нуля. Перед каждым измерением образец предварительно размагничивался в переменном магнитном поле с убывающей до нуля амплитудой. Типичные спектры, измеренные в области $T_{c m}$, приведены на рис. 2. Они представляют собой суперпозицию двух зеемановских секстетов, обусловленных ионами железа в $a$ - и $d$ подрешетках феррита $\left\{\mathrm{Gd}_{3}^{3+}\right\}_{c}\left[\mathrm{Fe}_{2}^{3+}\right]_{a}\left(\mathrm{Fe}_{3}^{3+}\right)_{d} \mathrm{O}_{12}^{2-}$. Следует отметить, что мессбауэровский спектр не различает симметричные и антисимметричные ориентации магнитных моментов ионов в подрешетках микрочастиц феррита относительно направления распространения $\gamma$-лучей (рис. 3), поскольку $\left(\sin \left(180^{\circ}+\alpha\right)=-\sin \alpha\right)$ относи- тельные площади линий поглощения мессбауэровского спектра ядер ${ }^{57} \mathrm{Fe}$ определяются квадратами тригонометрических функций (2). Учитывая это, параметр $k$ можно определить как отношение интегральных площадей линий поглощения мессбауэровского спектра, соответствующих $a$ - и $d$-подрешеткам феррита. Из изложенного выше также следует, что в методе анализа доменной структуры в микрочастицах магнитных порошков на основе мессбауэровской спектроскопии частицы могут иметь ферромагнитное или ферримагнитное упорядочение. В том и другом случае результаты, полученные по мессбауэровским спектрам, будут одинаковыми. Площади линий поглощения мессбауэровских спектров определялись с помощью программы UnivemMS. Для параметра $k$ получены следующие данные: при $T=T_{c m}+2 \mathrm{~K}$ $k=0.26 \pm 0.04$, при $T=T_{c m}+33 \mathrm{~K} \quad k=0.45 \pm 0.04$, при $T=T_{c m}+45 \mathrm{~K} k=0.64 \pm 0.04$. Видно, что вблизи $T_{c m}$ частицы феррита однодоменны. С удалением от $T_{c m}$ частицы переходят в многодоменное состояние, причем по мере удаления от $T_{c m}$ растет количество доменов в частицах. Аналогичная картина наблюдалась и в области температур ниже $T_{c m}$. В доменной структуре домены занимают значительно больший объем, чем доменные стенки, поэтому рост параметра $k$ с удалением от $T_{c m}$ главным образом происходит за счет увеличения количества замыкающих доменов, которые намагничены под углом к осям легкого намагничивания.

Следует отметить, что частицы феррита вблизи $T_{c m}$ слабомагнитны, поэтому при комнатной температуре в процессе изготовления образца частицы не прилипали друг к другу, и изотропность образца обеспечивалась автоматически. На практике чаще применяют сильномагнитные материалы, однодоменные частицы которых как элементарные магниты могут прилипать друг к другу, образуя цепочки, комки, что может нарушить изотропность образца, заложенную в основе предлагаемого метода. Поэтому образцы следует изготовлять при температурах выше, чем температура Кюри $T_{c}$, подобрав связующее вещество, твердеющее вблизи $T_{c}$.

\section{Конфликт интересов}

Авторы заявляют, что у них нет конфликта интересов.

\section{Список литературы}

[1] Крупичка С. Физика ферритов и родственных им магнитных окислов. М.: Мир, 1976. 353 с.

[2] Сергеев В.В., Булыгина Т.И. Магнитотвердые материалы. М.: Энергия, 1980. 224 с.

[3] Преображсенский А.А., Бишард Е.Г. Магнитные материалы и элементы. М.: Высш. шк., 1986. 532 с.

[4] Алиев М.Ш., Камилов И.К., Алиев М.Ш., Ибаев Ж.Г. // Письма в ЖТФ. 2016. Т. 42. В 3. С. 11-15.

[5] Чуев М.А. // Письма в ЖЭТФ. 2013. Т. 98. В. 8. С. 523-528.

[6] Чуев М.А. // Письма в ЖЭТФ. 2014. Т. 99. В. 5. С. 319-324. 
[7] Урусов А.Е., Петракова А.В., Жердев А.В., Дзантиев Б.Б. // Рос. нанотехнологии. 2017. Т. 12. № 9-10. C. 3-13.

[8] Козловский А.Л., Корольков И.В., Ибрагимова М.А., Здоровеи М.В., Кутузов М.Д., Николаевич Л.Н., Шумская Е.Е., Канюков Е.Ю. // Рос. нанотехнологии. 2018. T. 13. № 5-6. C. 118-123.

[9] Иркаев С.М., Кузьмин Р.Н., Опаленко А.А. Ядерный гамма-резонанс. М.: Изд-во МГУ, 1970. $207 \mathrm{c.}$

[10] Барьяхтар В.Г., Яблонский Д.А. // ФТТ. 1974. Т. 16. В. 11. C. 3511-3513.

[11] Логгинов А.С., Мешков Г.А., Николаев А.В., Пятаков А.П. // Письма в ЖЭТФ. 2007. Т. 86. В. 2. С. 124-129.

[12] Logginov A.S., Meshkov G.A., Nikolaev A.V., Nikolaeva E.P., Pyatakov A.P., Zvezdin A.K. // Appl. Phys. Lett. 2008. V. 93. N 18. P. 182510 (1-6).

[13] Звездин А.К., Пятаков А.П. // УФН. 2009. Т. 179. № 8. C. $897-904$.

[14] Рабкин Л.И., Соскин С.А., Эпштейн Б.Ш. Ферриты. Л.: Энергия, 1968. $384 \mathrm{c}$. 